\title{
CENTRALIDAD, RURALIDAD Y DINÁMICAS ECONÓMICAS-PRODUCTIVAS DEL NOROCCIDENTE DEL DISTRITO METROPOLITANO DE QUITO
}

\author{
DIANA MASSA \\ Investigadora independiente \\ Recepción manuscrito: 15 de marzo de 2016 \\ Aceptación versión final: 29 de abril de 2016
}

\begin{abstract}
RESUMEN En el presente artículo se hace una lectura de las centralidades en la ruralidad del noroccidente del Distrito Metropolitano de Quito (Gualea, Pacto, Nanegal y Nanegalito) a través de sus dinámicas económicas-productivas que reflejan contextos, procesos históricos, decisiones político-administrativas nacionales y locales atravesadas por visiones de desarrollo que subyacen al sistema capitalista. Las centralidades en los territorios rurales responden a características y dinámicas propias de estos espacios, que generan atracción de flujos, concentración de actividades, y que a su vez evidencian relaciones de jerarquía entre sujetos sociales y territorios.
\end{abstract}

PALABRAS CLAVE Centralidad, territorio, dinámicas territoriales.

ABSTRACT In this article, we made a reading of the centralities in rural northwestern Metropolitan District of Quito (Gualea, Pacto, Nanegal and Nanegalito) through their productive-and-economic dynamics, which reflect contexts, historical processes, national and local political-administrative decisions, which have been influenced by development visions underlain by the capitalist system. The centralities of the rural territories respond to their own characteristics and dynamics, which generate flux attraction, concentration of activities, which, in turn, make hierarchical relationships evident between social subjects and territories.

KEYWORDS Centrality, territory, territorial dynamics.

JEL CODES B59, O13, O18.

\section{INTRODUCCIÓN}

Históricamente ha sido dificultoso comprender el mundo rural, ligado esto siempre a miradas de desarrollo regional asociadas a su vez a las estrategias de las grandes ciudades y a su crecimiento poblacional. Es así que este trabajo ${ }^{1}$ aporta e invita a hacer una lectura de los territorios con dinámicas locales y rurales a partir del entendimiento de microrrealidades que llevan implícitas relaciones, contradicciones y problemas a nivel de su dimensión espacial interna y externa - problemas que generan importantes transformaciones en el territorio y contextos que promueven mecanismos de inclusión y rechazo-. A partir de esta realidad se configuran 
relaciones desiguales entre los territorios y surgen paradojas de las dinámicas rurales. Para poder tener un acercamiento y dimensión de lo que suscitan y construyen los territorios, se plantean entradas teóricas de uno de los factores que promueven dinámicas territoriales en los ámbitos rurales de América Latina y de Ecuador: las centralidades, que básicamente están relacionadas al manejo territorial desde la atractividad de flujos y la multifuncionalidad de los elementos propios de los territorios, según las decisiones de los gobiernos centrales y seccionales.

De ahí que este estudio pretende visualizar la realidad de las parroquias del noroccidente del Distrito Metropolitano de Quito (Nanegal, Nanegalito, Gualea y Pacto), en donde se puede identificar los procesos históricos que moldean su realidad a partir de las dinámicas sociales y económicas-productivas que responden a procesos migratorios (inmigración y emigración) en relación a la urbe, y a los auges y declives de las plazas laborales.Cabe mencionar, que si bien en este análisis se hace referencia a las dinámicas económicas y productivas en los territorios rurales a nivel del noroccidente de Quito, las dinámicas no solo se enfocan en actividades económicas-productivas, sino también hacen referencia a identidades, memorias, manifestaciones culturales, relaciones simbólicas y prácticas comunitarias que denotan el sentido de pertenencia y valoración del territorio.

\section{CONCEPTUALIZANDO LAS CENTRALIDADES}

En los territorios se suscitan y construyen dinámicas territoriales que hacen referencia a los cambios, los procesos, los movimientos y las transformaciones sociales. Estas dinámicas territoriales pueden ser de comercialización, distribución poblacional, geográfica. Sin embargo, estas dinámicas territoriales y sus efectos no están exclusivamente determinadas al interior del territorio, ya que existen diversos factores y/o tendencias externas a nivel económico, político, cultural, ambiental y social, intensificadas por la globalización, cuya influencia es directa o indirecta en la estructura, reestructura y dinámicas del desarrollo de los territorios (RIMISP, 2008).

Entendemos a los territorios como espacios multidimensionales que se construyen y constituyen a partir de las relaciones sociales, y éstas son relaciones de poder. Por tanto, el ejercicio del poder que se construye en el territorio pasa por determinados procesos y dinámicas a nivel local y global que básicamente responden a intereses sociopolíticos y socioculturales (Sosa, 2012). Estas relaciones de poder que siempre están implícitas en prácticas espaciales y temporales (Harvey, 1998), son tanto materiales como simbólicas y constituyen el resultado de la construcción de un espacio a partir de la dimensión social — humana, social, económica, cultural, ambiental, política-. En este sentido, el territorio es más que el espacio físico y geográfico en el que se desarrolla una comunidad; es una construcción social, donde en la interrelación de los actores sociales se despliegan distintas estrategias para organizar y distribuir los recursos económicos, sociales, políticos y culturales.

De esta forma, las dinámicas territoriales que se construyen por el crecimiento demográfico y la expansión de centros urbanos, han desencadenado en la transformación de las formas de organización territorial y en la asignación de nuevos significados urbanos a las sociedades; por tanto, modificándose también aspectos como la movilidad y la accesibilidad, según las actividades cotidianas de los pobladores. Cabe mencionar que la transformación de las formas 
espaciales o de organización territorial responde no solo a procesos sociales, sino también ambientales, económicos, culturales y, en general, espaciales, que giran alrededor de tendencias históricas en base a intereses dominantes.

Para la óptica de Raffestein (2011), la cohesión de las relaciones económicas, la ciencia y la tecnología dan origen a las grandes centralidades. Las relaciones construidas en base al crecimiento económico también producen efectos de marginalidad en los territorios. En este sentido, las transformaciones y efectos que se dan en el territorio como el desaparecimiento espacial o la fragmentación, también responden a los procesos de homogeneización desde el neoliberalismo y la globalización. De ahí surge la idea de mirar estos fenómenos en relación a las escalas; es decir, lo que sucede a pequeña y gran escala responde a problemas estructurales y del sistema mundial, cuya representación espacial y simbólica está ligada a la idea de centro y periferia u organizaciones en situación de centralidad o de marginalidad (Raffestein, 2011). Hay que tomar en cuenta que, desde un recorrido histórico, la construcción del concepto de centralidad ha estado ligado a los procesos de estructuración urbana, cuya representación es de orden espacial y geométrico, como la Teoría de los Lugares Centrales de Walter Christaller (1933), cuya propuesta teórica es la distribución urbana de las ciudades en el espacio a través del área de influencia en relación al mercado, donde se establece una relación fundamental entre el lugar y la función.

A partir de este planteamiento se hace necesario también profundizar la realidad del sistema de relaciones que se construye a partir de los lugares centrales. Para Raffestein (2011) la presencia de lugares de agrupación o nudosidades en base a relaciones económicas, la ciencia y la tecnología provocan discontinuidades en la distribución u ordenamiento del espacio. Por tanto, esta caracterización espacial de los lugares centrales remite a las relaciones de poder y dominación que se ejercen en esta distribución espacial; de ahí que las relaciones de poder también se vinculan a hablar de organizaciones o de grupos en situación de centralidad y de organizaciones, o de grupos en situación de marginalidad. Dentro de esta lógica, Raffestein (2011) también expresa a la ciudad capital como centralidad, donde se concretizan materialmente las estrategias nacionales. Es así que la configuración de un espacio-temporal no es autónomo: depende de las intenciones y acciones que se deciden desde un poder central, sean actores sociales o institucionales. Por tanto, la centralidad modela los contextos desde su propia perspectiva, ya sea de una manera parcial o total. Esta centralidad puede ser multidimensional o únicamente de carácter política, económica o cultural. De esta manera, la centralidad puede manifestarse en una sola ciudad o en muchas, pero no exime que la marginalidad se manifieste en formas distintas.

En esta misma perspectiva Castells (1995) afirma que la centralidad puede abordarse desde los ámbitos económicos, político-institucional, ideológico y de modos de relaciones sociales. En ese sentido, si bien Carrión (1987) considera que la formación de centralidades depende de la concentración de ciertas funciones urbanas y la centralización de actividades con una función integradora, no implica, según Lefebvre (1973), que estos lugares se conviertan en lugares de interacción en los cuales los ciudadanos se representan, se identifican y se apropian de su territorio a través del tiempo. Teniendo en cuenta los elementos básicos que constituyen el concepto de centralidad, podemos llegar a determinar que las centralidades son entendidas 
como espacios articuladores a nivel social, cultural, económico-productivo, ambiental y político, que concentran una serie de bienes, actividades y servicios para los habitantes del entorno. Estos espacios centrales atraen flujos y generan conectividad con su entorno, ocasionando externalidades o impactos, ya sean positivos y/o negativos en su contexto y realidad territorial. Para Castells (2001), los flujos responden a los procesos que dominan nuestra vida a nivel político, económico y simbólico.

Es así que trasladar este concepto de centralidad al entorno rural, implica tomar en cuenta el contexto y/o realidad territorial, como su demografía, paisaje, mercados, relaciones sociales de producción con la urbe y todas las características propias del lugar, que generen atracción de flujos, concentración de actividades y construyan jerarquías. De igual manera, en las áreas rurales, las dinámicas territoriales dependen de las articulaciones entre la ciudad y el campo, así como también con el hecho de que la concentración de equipamientos y servicios es disfuncional, debido a las bajas densidades poblacionales, a las grandes distancias entre poblaciones y a la dificultad de accesibilidad de algunos sectores.

\section{LAS CENTRALIDADES EN LA RURALIDAD A PARTIR DE LAS} DINÁMICAS TERRITORIALES ECONÓMICAS PRODUCTIVAS

A manera de contexto, este estudio de caso se localiza en el noroccidente del Distrito Metropolitano de Quito (DMQ), en la provincia de Pichincha. Este territorio es parte de la microrregión del noroccidente del DMQ, la misma que está conformada por cuatro parroquias rurales: Nanegal, Nanegalito, Gualea y Pacto. El territorio tiene una topografía diversa, responde a la zona de media y baja montaña, con temperaturas que oscilan entre los 20 y 24 grados centígrados, correspondientes a un clima cálido-húmedo. Se encuentra en una elevación entre los 700 y $1800 \mathrm{~m}$ sobre el nivel del mar.

A partir de los elementos teóricos, conceptuales y territoriales mencionados en los párrafos anteriores, se propone hacer un análisis de las centralidades en las ruralidades del noroccidente de Quito, a partir de las dinámicas territoriales económicas-productivas. En ese sentido, para este análisis las variables ${ }^{2}$ que dinamizan el territorio se han convertido en rasgos diferenciadores que marcan el contraste entre las parroquias rurales del Noroccidente de Quito, que son: actividades económicas-productivas, concentración de servicios básicos, accesibilidad por medio de vías y transporte público, y distribución y tasas de crecimiento poblacionales.

\section{AGRICULTURA: CAÑA DE AZÚCAR Y DERIVADOS}

Dentro de las actividades económicas más importantes y tradicionales en las parroquias del noroccidente del DMQ, de manera específica en Gualea, Pacto y Nanegal, se encuentra el cultivo de caña de azúcar y la producción de panela en polvo y bloque, como también del aguardiente, entre los territorios han estado vigentes condiciones diferenciadoras, inequitativas y poco sostenibles con el medio ambiente. A partir de la construcción de la carretera Quito-NonoNoroccidente se dinamiza la explotación de bosques primarios para el comercio de la madera. Este hecho, y la necesidad de implementar límites a las propiedades, impulsaron el auge de la producción de caña de azúcar en Nanegal, Pacto y Gualea, ya sea como panela o aguardiente 
- producción que fue afectada por coyunturas sociales que se vivían a través de la ley de estancos y la dolarización-. Para la segunda mitad del siglo xx, la apertura de la vía Calacalí-La Independencia, permitió que Pacto logre incrementar su producción de caña y se traslade a más lugares del noroccidente de Pichincha (Instituto de la Ciudad, 2012).

\section{GANADERÍA}

A partir de la década de los 90 o finales del siglo $\mathrm{xx}$, en las parroquias del noroccidente de Quito, se da una presencia importante de la ganadería bovina, a raíz del declive de la producción de caña de azúcar y otros productos como la naranjilla y el plátano. En el caso de Nanegalito, existe una presencia importante de ganado porcino, cuya demanda es grande por la elaboración de la fritada en los restaurantes y picanterías de la carretera (Espinosa, 2005). La producción de leche se da en mayor escala en Nanegalito y Pacto, pero en Gualea y Nanegal es menor. Por ejemplo, en Nanegalito, existen microempresas como centros de acopio de leche y de la producción de derivados (рDOт Nanegalito, 2012).

En general, en Gualea no hay procesamiento de derivados con equipos industriales, sino sólo artesanalmente para consumo doméstico. En estos dos últimos años se ha empezado a procesar queso, yogur y manjar (РDОт Gualea, 2012). La mayor parte de la producción lechera es comercializada a través de intermediarios y con empresas anclas como Nestlé, Rey Leche y El Ordeño. Cabe mencionar que la presencia de una empresa transnacional como la Nestlé, ha llevado al monopolio de los mercados de leche en toda la región, situación que conlleva a que las condiciones de negociación no sean justas para los productores. Nanegal, Nanegalito y Pacto, tienen como compradores a la Nestlé y a empresas nacionales. En el caso de Gualea, sus compradores son Rey Leche y El Ordeño.

PECUARIA

En el sector pecuario también existe la cría de animales de granja como pollos, gallinas, chanchos, truchas y tilapias, ya sea para consumo doméstico o para la comercialización local y externa a la zona. El sistema de crianza de cerdos se maneja en torno a dos aspectos, por un lado para el abastecimiento local y por otro para el de mercados o tercenas de Quito e Ibarra. En las parroquias de Nanegalito y Nanegal se encuentran criaderos de cerdos del grupo PRONACA, que sirven para el faenamiento y abastecimiento de su cadena de comercialización (Instituto de la Ciudad, 2012).

Para la producción avícola, «se encuentran en Nanegal granjas o plantas avícolas de las siguientes empresas: Grupo Oro y PROFAsA, donde se crían y cuidan a las aves. Para el faenamiento, las aves son llevadas fuera de la zona del noroccidente del DMQ, como a Yaruquí. En el Grupo Oro, están empleadas muchas personas de la misma zona, pero también hay gente de Loja y de Manabí» (Instituto de la ciudad, 2012, p. 97, РDOT Nanegal, 2010, pp. 52-53). La piscicultura se ha desarrollado en gran medida en Pacto y Nanegal, y en estos dos últimos años, está incursionando en Gualea a través de una asociación denominada PAAMAC. Pacto cuenta con pequeños estanques destinados para el autoconsumo, hasta criaderos con varias piscinas donde la producción es destinada a mercados en Quito y Los Bancos. Por su parte, Nanegal cuenta con el Centro Piscícola Nanegal del Gobierno Provincial de Pichincha, siendo un centro 
de investigación para formación de semillas certificadas (alevines). Tienen en 20 estanques tilapia roja y africana, carpa israelita, escamada y espejo, donde se puede observarlos criaderos de peces. A este centro piscícola acuden dueños de criaderos de Nanegal, Nanegalito, Pacto y Gualea, incluso de otras zonas del noroccidente de Pichincha para comprar los peces (PDOT Nanegal, 2010).

\section{TURISMO COMO SERVICIO PRIVADO Y ACCIÓN COMUNITARIA}

El turismo en la zona del noroccidente del Distrito Metropolitano de Quito ha tomado un impulso mayor en estos últimos 12 años, ya que existen accesos viales que han permitido dinamizar el comercio y el ingreso de turistas nacionales y extranjeros. Asimismo, el turismo se sustenta porque en esta zona noroccidental se cuenta con la primera área de conservación metropolitana, que contempla las microcuencas de los ríos Mashpi, Guaycuyacu y Sahuangal (17.157 ha) (Plan Nacional Buen Vivir 2013-2017, p. 2013).

En este sentido, en las cuatro parroquias noroccidentales han surgido emprendimientos turísticos de carácter privado como también comunitario, liderado por las juntas parroquiales o familias de la localidad. Varios de estos emprendimientos están relacionados con un turismo ecológico, cultural y de aventura. En las cuatro parroquias, existen atractivos turísticos que son de propiedad privada y otros que son declarados reservas naturales. En esta línea, existen dos reservas representativas del noroccidente de Quito, en Nanegalito se encuentra la Reserva Orquideológica El Pahuma donde existe una gran variedad de flora y fauna, de manera específica una diversidad de orquídeas. De igual manera, en Nanegal, existe un gran referente del ecoturismo, como la Reserva Maquipucuna, que se encarga de la protección y conservación del medio ambiente, tiene una extensión de 6000 ha llenas de gran diversidad, variedad de especies de aves, mariposas exóticas, especies de plantas y de mamíferos (PDOT Nanegal, 2010).

Por otro lado, en estas cuatros parroquias se puede observar que el turismo sigue siendo una actividad complementaria en comparación a otros sectores como Yunguilla y Mindo, donde el turismo se ha convertido en una actividad predominante que incluso ha hecho de lado a la ganadería y la agricultura. Esto, sin olvidar que las actividades turísticas son complementarias a las otras actividades productivas y económicas — ganadería, producción avícola, piscicultura, agricultura - que se desarrollan en el ámbito rural.

Nanegalito tiene una condición geográfica distinta a las tres parroquias (Nanegal, Gualea y Pacto), ya que la vía de acceso Calacalí-La Independencia y la cercanía a la ciudad capital, han permitido el ingreso permanente de visitantes que en su mayoría se encuentran en un estado de paso hacia otros destinos. Es así que con el paso de los años, el comercio y la prestación de servicios como restaurantes, tiendas, complejos, paraderos y hosterías, hayan potenciado el desarrollo turístico como una de las principales fuentes económicas de la parroquia (РDOT Nanegalito, 2012).

\section{MINERÍA}

En el año 1996 ingresa la actividad minera a la parroquia de Pacto, la misma que se ha realizado a través de túneles o a cielo abierto. Hoy en día, existen 15 concesiones mineras inscritas, de las cuales 3 han estado en etapa de explotación, sin embargo, varias veces han sido clausuradas, ya 
que su funcionamiento ha sido ilegal por no contar con permisos, ni tampoco han cumplido con el debido proceso de consulta y participación ciudadana (рDот Gualea, 2012).

En las parroquias de Nanegal y Nanegalito no ha existido actividad extractiva minera, ni concesiones mineras en cuanto a oro o una serie de metales como plata, cobre, uranio (PDOT Nanegal, 2010). Ante la inconformidad y presión de los moradores de Pacto y de las parroquias aledañas, se logró que en el año 2008 los tres alcaldes de los cantones del noroccidente de Pichincha - Pedro Vicente Maldonado, San Miguel de Los Bancos y Quito- declaren a esta zona libre de minería, puesto que los daños ambientales y sociales que ocasiona la actividad minera son irreversibles. Sin embargo, el Municipio de Pedro Vicente Maldonado, el Municipio de San Miguel de Los Bancos y el Gobierno Provincial de Pichincha explotan material pétreo para arreglar caminos vecinales, lo que ha ocasionado impacto negativo sobre los sistemas hídricos de los ríos Mashpi y Pachijal (РDот Gualea, 2012).

En ese sentido, en los años 2013 y 2014 en Pacto se desarrolló una manifestación por parte de los habitantes de las cuatro parroquias del noroccidente, para rechazar la gestión y manejo de la socialización de las concesiones mineras Urcutambo e Ingapi por parte de la Empresa Nacional Minera del Ecuador ENAMI, proyecto minero que impactará en zonas de las Parroquias de Pacto y Gualea, declaradas como áreas protegidas por el Distrito Metropolitano de Quito. Durante todos estos años, se han generado conflictos entre empresas mineras y varios miembros de la comunidad algunos a favor y otros en contra. Se han creado diferencias significativas entre las parroquias del noroccidente del DMQ, dado que Pacto concentra la mayor cantidad de concesiones mineras que tiene ENAMI en relación a esta microrregión. En este sentido, este territorio se identifica como centralidad, por ser una fuente de extracción de recursos no renovables, que motiva a varias poblaciones de las parroquias aledañas o del país, para ser partícipes de esta actividad laboral. Lo que implica, movilidad y crecimiento poblacional de esta parroquia, en comparación al resto de territorios de la zona noroccidental, donde esta actividad se encuentra en menor escala o es nula.

\section{ACCESO A SERVICIOS BÁSICOS}

A nivel nacional, la cobertura de agua potable y alcantarillado da cuenta de las diferencias territoriales que existen en las zonas urbanas y rurales. «Al 2011, el porcentaje de viviendas con acceso a la red pública de agua alcanzó el 35,4\% en zonas rurales, frente al 93,2\% en áreas urbanas» (Plan Nacional del Buen Vivir, 2013, p. 113). Con respecto al abastecimiento de agua potable por red pública, la mitad de la población de las parroquias de Nanegal y Nanegalito se abastece de agua por este medio y en menor medida Gualea y Pacto (ver Tabla 1). El abastecimiento de agua potable por red pública aún es exclusivo para los barrios más poblados y cercanos a las vías principales por cuanto los diseños de planificación fueron elaborados sin considerar el crecimiento poblacional fuera de las áreas urbanizables. De ahí, que una parte de la población de cada parroquia carece de este servicio. Aparte de la red pública, existen otras fuentes de procedencia del agua; en este sentido, la mitad de la población de cada parroquia se abastece de agua proveniente de caudales de ríos y vertiente, siendo común en asentamientos humanos dispersos. En menor medida, utilizan pozos, carros recolectores u otros mecanismos como el agua de lluvia. 
Asimismo, para determinar la cobertura de alcantarillado dentro de las parroquias se ha tomado en cuenta la conexión que tienen en relación al servicio higiénico. De esta manera se identifica que en las cuatro parroquias existe un déficit de cobertura de este servicio. Es importante mencionar que el sistema de aguas servidas o alcantarillado se encuentra con mayor medida en los barrios de las cabeceras parroquiales, eso significa que las poblaciones - barrios, comunidades, fincas - que se encuentran alejadas de los centros poblados, no cuentan con alcantarillado. A nivel nacional, «la cobertura de alcantarillado llega al 18,3\% de las viviendas rurales y al 86,5\% de las urbanas» (Plan Nacional Buen Vivir, 2013, p. 113).

A pesar de que las cuatro parroquias cuentan con un déficit del servicio de alcantarillado, Gualea es la parroquia del noroccidente del DMQ que tiene menor cobertura de alcantarillado en sus barrios, en comparación al resto de parroquias aledañas (ver Tabla 2). Este punto también nos invita a reflexionar cómo es la capacidad de gestión de los gobiernos locales al momento de exigir y presionar a las instituciones del gobierno, el cumplimiento de obras prioritarias para sus territorios. De esta manera, también se podrá identificar otras causas u orígenes para que las poblaciones se encuentren en una posición de centro o periferia. En continuidad con el alcantarillado, existe una carencia de un sistema de recolección de desechos sólidos y líquidos en las parroquias del noroccidente del DMQ, eso implica que son depositadas de manera directa al alcantarillado y éste a su vez a los ríos o quebradas. Así como existe un déficit en la cobertura de alcantarillado, también se cuenta con un grado de contaminación por desfogue de aguas negras o servidas es alto (ver Tabla 3).

De la misma manera, en estos resultados Gualea sobresale ante las otras parroquias del noroccidente por tener una baja conexión del servicio higiénico a la red pública, este dato se sustenta por la falta de cobertura de alcantarillado en la parroquia, por tanto, en Gualea existen otras formas para eliminar los desechos sólidos y líquidos, como es el caso de los pozos sépticos y los pozos ciegos. Es importante tomar en cuenta que el pozo séptico se considera como saneamiento adecuado en zonas rurales, no así el pozo ciego. Eso expone que en Gualea el manejo de aguas negras aún es más bajo en relación a las otras parroquias y además, existe una mayor probabilidad de que estos desechos sean descargados directamente al medio natural.

Por otro lado, el alcance del servicio de energía eléctrica en las cuatro parroquias es de casi el 100\%, eso implica que la cobertura es amplia y casi totalitaria en todo el territorio que corresponde a estas parroquias. Sin embargo, el poco porcentaje de asentamientos humanos que no tienen cubierto el servicio de energía eléctrica, responden a comunidades y fincas alejadas. Según los datos del INEC (2010), esta realidad se sustentaría con los logros alcanzados a nivel nacional dentro del ámbito de la electrificación rural «cuya cobertura alcanzo el 89,5\% de viviendas en 2010, valor muy superior al 53,8\% prevaleciente en 1990» (Plan Nacional del Buen Vivir 2013-2017, 2013, p. 137). La procedencia de la energía eléctrica que predomina ya sea para servicio domiciliario o público en cada una de las parroquias, es por medio de la red de empresa eléctrica (ver Tabla 4). Existe un promedio del 5\% de población que no tiene luz, por ello utilizan paneles solares o generadores de luz para obtener esta energía dentro de sus hogares o terrenos. No existe una diferencia significativa entre las parroquias.

La cobertura de la recolección de basura es diferenciada en las cuatro parroquias, por un lado, Nanegal, Nanegalito y Gualea cuentan con la mayor cobertura de este servicio básico 
Tabla 1. Procedencia principal del agua recibida según parroquias noroccidente de Quito

\begin{tabular}{lcccc}
\hline & \multicolumn{4}{c}{ PARROQUIAS NOROCCIDENTE DMQ } \\
PROCEDENCIA PRINCI- & GUALEA & NANEGAL & NANEGALITO & PACTO \\
\cline { 2 - 5 } PAL DEL AGUA RECIBIDA & 44,9 & 65,9 & 58,0 & 40,7 \\
\hline Red pública & 2,7 & 1,3 & 2,4 & 0,9 \\
Pozo & 44,4 & 31,2 & 37,2 & 56,5 \\
Río, vertiente, acequia o canal & 0,0 & 0,0 & 0,2 & 0,0 \\
Carro repartidor & 8,1 & 1,6 & 2,2 & 2,0 \\
Otro (agua lluvia/albarrada) & & & & \\
\hline
\end{tabular}

Fuente: INEC (2010).

Tabla 2. Servicios de alcantarillado y recolección de basura

\begin{tabular}{lcc}
\hline PARRoquias & $\begin{array}{c}\text { ALCANTARILLADO/CONEC- } \\
\text { TADO A RED PÚBLICA }\end{array}$ & $\begin{array}{c}\text { ELIMINACIÓN DE BASURA } \\
\text { POR CARRO RECOLECTOR }\end{array}$ \\
\hline Gualea & 13,42 & 61,36 \\
Nanegal & 39,76 & 66,45 \\
Nanegalito & 39,37 & 68,41 \\
Pacto & 27,74 & 34,14 \\
\hline
\end{tabular}

Fuente: INEC (2010).

Tabla 3. Tipo de servicio higiénico o escusado según parroquias noroccidente DMQ

\begin{tabular}{|c|c|c|c|c|}
\hline \multirow{2}{*}{$\begin{array}{l}\text { TIPO DE SERVICIO HI- } \\
\text { GIÉNICO O ESCUSADO }\end{array}$} & \multicolumn{4}{|c|}{ PARROQUIAS NOROCCIDENTE DMQ } \\
\hline & GUALEA & NANEGAL & NANEGALITO & РАСТО \\
\hline $\begin{array}{l}\text { Conectado a red pública de } \\
\text { alcantarillado }\end{array}$ & 13,4 & 39,8 & 39,4 & 27,7 \\
\hline Conectado a pozo séptico & 48,7 & 22,9 & 36,5 & 40,9 \\
\hline Conectado a pozo ciego & 19,5 & 11,5 & 13,1 & 19,9 \\
\hline $\begin{array}{l}\text { Con descarga directa al mar, } \\
\text { río, lago o quebrada }\end{array}$ & 5,9 & 17,2 & 6,9 & 2,9 \\
\hline Letrina & 3,6 & 1,3 & 1,5 & 1,3 \\
\hline No tiene & 8,9 & 7,4 & 2,7 & 7,2 \\
\hline
\end{tabular}

Fuente: INEC (2010).

frente a Pacto (ver Tabla 2), a pesar de que esta última sea la que tiene mayor población y superficie, el manejo de desechos en la parroquia de Pacto es inadecuado y, además, se limita a la cabecera parroquial y a dos barrios cercanos al centro urbanizables: Pactoloma y la Delicia, es así que en la parroquia existe un foco infeccioso de desechos (Рдот Pacto, 2012). En las cuatro parroquias, otras formas de eliminación de basura son a través del arrojo en terreno baldío 
o quebrada, o a su vez, la queman. En el caso de la eliminación de basura por carro recolector, es labor la realiza la Empresa Pública Metropolitana de Aseo de Quito, EMASEO, quien se encarga de recolectar la basura de las cabeceras parroquiales y barrios aledaños, y con menor frecuencia visita los barrios que se encuentran distantes a los centros parroquiales. Por ende, muchas personas optan por otros medios para eliminar la basura (PDOT Nanegalito, 2012, PDOT Gualea, 2012 у рDОт Nanegal, 2010).

\section{MOVILIDAD, VÍAS Y TRANSPORTE PÚBLICO}

Históricamente, la gestión, acceso a vías y transporte público han generado hitos y diferencias importantes en las cuatro parroquias del noroccidente, ambos ligados a la movilidad de las poblaciones y el acarreo de sus productos desde el monte hasta sitios donde llegaba el camión (Espinosa, 2005). El sistema de transporte está dado en función de las actividades político-administrativas y económicas de la población. Principalmente las poblaciones beneficiadas por los medios de transporte son las que se encuentran en la cabecera parroquial y que tienen una dirección a la ciudad central Quito o que tienen interconexión con la vía Calacalí-La Independencia. Muchas de las poblaciones que están conectadas con zonas productivas, tienen grandes limitaciones de acceso y movilidad. Esta realidad nos confirma nuevamente que la situación vial y de transporte en la que se encuentra Nanegalito hace que esta parroquia se convierta en un centro de conexión y movilidad para el resto de las parroquias de la zona.

\section{DISTRIBUCIÓN Y TASAS DE CRECIMIENTO POBLACIONALES}

Las cuatro parroquias cuentan con un territorio de 94.818 ha, que representa el $22,4 \%$ del territorio total del Distrito Metropolitano de Quito y acoge a 12.485 habitantes. El número de habitantes de la microrregión con respecto al total de población del DMQ (2.239.191 habitantes), representa el o,56\%. Ahora bien, la mayoría de barrios o comunidades dentro de las parroquias tienen un modo de vida rural, de manera que las actividades cotidianas de los habitantes están vinculadas al agro. En esta misma línea, según los datos del Censo de Población y Vivienda 2010, la mayor concentración de población en las parroquias del Noroccidente del DMQ, se encuentra en Pacto, seguida de Nanegalito. Para el caso de las parroquias de Gualea y Nanegal responden a territorios donde la concentración de la población es menor. Asimismo, la distribución territorial en las cuatro parroquias es diferenciada.Pacto ocupa el mayor espacio territorial con $346.34 \mathrm{~km}^{2}$, es decir, el $37 \%$ de la superficie en $\mathrm{km}^{2}$, al igual que Nanegal. Al contrario de Nanegalito y Gualea donde el espacio territorial que ocupan es reducido, el $13 \%$.

Estos datos nos permiten confirmar que la configuración de una centralidad también está relacionada por su espacio territorial y concentración de la población. Por este motivo, se entiende que Pacto se convierte en una centralidad por que cumple con estos dos factores, al contario de Gualea que es un territorio con poca población y espacio geográfico. Asimismo se evidencia cómo el crecimiento poblacional de las cuatro parroquias ha sido variable en el período 2001-2010 (ver Tabla 5), es importante considerar que los procesos migratorios, acompañados por las dinámicas productivas, han constituido desequilibrios en el crecimiento poblacional y económico-productivo entre las parroquias, ocasionando diferencias como es el caso de Pacto y Gualea. En este sentido, en el año 2000 la crisis económica que vivió el país 
Tabla 4. Procedencia de luz eléctrica según parroquias noroccidente DMQ

\begin{tabular}{lcccc}
\hline \multirow{2}{*}{$\begin{array}{l}\text { PROCEDENCIA DE } \\
\text { LUZ ELÉCTRICA }\end{array}$} & GUALEA & NANEGAL & NANEGALITO & PACTO \\
\cline { 2 - 5 } Empresa servicio público & 95,0 & 94,6 & 96,8 & 91,4 \\
Panel solar & 0,0 & 0,0 & 0,0 & 0,2 \\
Generador de luz (planta el.) & 0,7 & 0,3 & 0,4 & 0,2 \\
Otro & 0,2 & 0,3 & 0,1 & 0,5 \\
No tiene & 4,1 & 4,9 & 2,8 & 7,8 \\
\hline
\end{tabular}

Fuente: INEC (2010).

Tabla 5. Crecimiento poblacional de las 4 parroquias noroccidentales del DMQ

\begin{tabular}{lcc}
\hline PARROQUIAS & POBLACIÓN 2001 & POBLACIÓN 2010 \\
\hline Nanegal & 2.560 & 2.638 \\
Nanegalito & 2.474 & 3.028 \\
Pacto & 4.820 & 4.798 \\
Gualea & 2.121 & 2.025 \\
\hline
\end{tabular}

Fuente: INEC (2010).

provocó que pobladores de estas parroquias emigren a países como España, Italia y Estados Unidos. Es así que en el periodo censal 2001-2010, en las parroquias de Gualea y Pacto se observa que la población reduce, al contrario de las parroquias de Nanegal y Nanegalito donde la población sigue aumentando de manera paulatina.

\section{RASGOS DIFERENCIADORES DE LAS PARROQUIAS}

En general, articulando las variables de centralidad en la ruralidad descritas en los párrafos anteriores, se puede determinar rasgos diferenciadores entre Gualea y las parroquias aledañas como Nanegal, Nanegalito y Pacto, que además permiten reflexionar sobre la relación centro y periferia que se ha creado dentro de sus contextos y dinámicas territoriales. En este sentido, en Pacto y Nanegalito se ha impulsado el auge de la producción de caña de azúcar y con esto la apertura al mercado de panela y aguardiente, a lo que hay que añadir la construcción de vías de transporte para facilitar el comercio y la explotación de la madera de estas parroquias. Y, en contraste, se ubican Gualea y Nanegal como las comunidades más alejadas de la cabecera cantonal y, por consiguiente, menos favorecidas en cuanto al comercio y servicios.

En esta misma línea se evidenció que las diferencias en la actividad ganadera de leche y carne, se deben al procesamiento de la leche, la presencia de empresas de anclaje y el mercado de la carne. En base a estos factores, Gualea no cuenta para el procesamiento de la leche con equipos industriales, sino que ésta solo es artesanal y para consumo doméstico. Esta situación contrasta con Nanegalito, donde existen varias familias y organizaciones ganaderas que procesan la leche en varios derivados como queso, yogur y manjar. Asimismo, Nanegalito, Nanegal 
y Pacto, por tener como empresa ancla a una empresa transnacional como Nestlé, se diferencian de Gualea, la cual entrega su producción lechera únicamente a empresas de alcance nacional. Esta situación se repite con otras actividades productivas como la crianza de animales de granja como gallinas, pollos y cerdos, ya que las parroquias de Nanegal, Nanegalito y Pacto son parte de cadenas productivas y agronegocios de empresas como PRONACA, PROFASA y Grupo Oro. Por tanto, la presencia de estas empresas en estos territorios marca diferencias muy marcadas con Gualea, pues sus productos se orientan principalmente al autoconsumo o para comercializarlos con intermediarios locales.

Otros aspectos que se destacan en este análisis, son el ámbito turístico y minero. Claramente se puede evidenciar que Nanegalito concentra la actividad turística, puesto que su ubicación geográfica, el reconocimiento en el imaginario social y el acceso vial son sus tres aliados perfectos, para la promoción de sus servicios turísticos privados y comunitarios. De igual forma, Pacto sobresale por la concentración de la actividad minera, por el número de años dedicados a esta actividad y además, por el mayor número de concesiones extractivas. Estos factores han incidido en la movilidad de la población local y nacional. A nivel de servicios básicos y servicios sociales, Gualea se diferencia del resto de parroquias porque menos de la mitad de la población no tiene cobertura de alcantarillado. En este punto, también Pacto muestra una debilidad porque más de la mitad de su población tiene dificultades para la eliminación de basura. De manera general, las parroquias de Pacto y Nanegalito tienen la cobertura más alta de servicios básicos y sociales.

De esta manera se puede confirmar que la presencia de lugares como Nanegalito y Pacto, dentro de la zona del noroccidente del DMQ, representan una agrupación o nudosidad a nivel social y económico productivo, lo que ocasiona que estas parroquias generen discontinuidades en la distribución u ordenamiento del espacio de esta zona. Por tanto, las parroquias que no reflejan estas características (Gualea y Nanegal), se ven absorbidas por centros poblados, de negocios y comercio, a tal punto que su situación actual podría denominarse de marginalidad o periferia por ser las comunidades más desprovistas de acceso, comercio y servicios básicos. Por su parte, las parroquias de Pacto y Nanegalito han construido relaciones con el medio en base al crecimiento económico, desligadas de una mirada de desarrollo endógeno, que permita la cohesión y fortalecimiento de territorios aledaños con características similares para poder contrarrestar problemáticas estructurales a nivel nacional y regional que influyen directamente en los contextos y entornos rurales. De ahí la importancia de profundizar el sistema de relaciones o dinámicas que se construyen en los lugares centrales y aledaños de estesector del distrito metropolitano.

A partir de esta realidad se hace necesario, cada vez más, visualizar la construcción social de los territorios, considerando aspectos de organización y cultura, donde las parroquias rurales como Gualea y Nanegal, puedan fortalecer sus organizaciones sociales y económicas, con el fin de promover acciones en común o comunitarias y transformar sus territorios en espacios vivos que hagan frente a su condición geográfica y situación de pobreza o estancamiento que ha sido impuesta por el sistema capitalista a través de sus acciones y mecanismos ideológicos, políticos, económicos, militares y religiosos, que a nivel histórico han promovido la desaparición irreversible del mundo rural, la explotación del campo desde las ciudades y la falta 
de voluntad política en la formulación y planificación de políticas territoriales, donde lo rural deje de responder a una funcionalidad de las urbes.

\section{CONCLUSIONES Y PERSPECTIVAS}

A nivel histórico, la relación entre las parroquias rurales del Noroccidente de Quito por lo general ha estado ligada a una correlación económica, en el sentido que estas áreas rurales han sido productores de alimentos - leche y sus derivados, caña de azúcar, animales de granjay la urbe quiteña sus compradores y/o consumidores. Asimismo, estas parroquias rurales con sus propias dinámicas territoriales han construido vínculos o articulaciones con otros núcleos poblacionales o centros, como parroquias y/o cantones aledaños. Sin embargo, cabe resaltar que la urbe de Quito siempre ha sido un centro político administrativo, comercial, cultural y de formación educativa para los entornos rurales —en este caso las parroquias de Gualea, Pacto, Nanegal y Nanegalito-, estableciéndose una macrocentralidad articuladora. Es por ello que la presión del Distrito Metropolitano de Quito y del mercado, a través de sus diversos mecanismos, instituciones y políticas, también van a influir en las dinámicas económicas-productivas como también en el aumento o disminución de desequilibrios territoriales en los espacios rurales, tal como vimos en el punto anterior, en torno a los rasgos diferenciadores que marcan el contraste entre las parroquias del noroccidente del Distrito Metropolitano de Quito - agricultura, ganadería, turismo, minería, acceso a servicios básicos y crecimiento poblacional一.

Este trabajo forma parte de una investigación que busca analizar las dinámicas territoriales en la parroquia de Gualea a nivel social y económico a partir de los procesos de centralidad rural de la microrregión del noroccidente del DMQ, para evidenciar los modelos de desarrollo que se promueven en las zonas rurales, sus influencias y las repercusiones. Estas imposiciones del desarrollo se manifiestan a través de la mercantilización de la tierra, la migración, la construcción de vías de transporte y de comunicación y los encadenamientos productivos. Poco se han pensado las centralidades en los territorios rurales, puesto que es una categoría conceptual que históricamente se ha ligado a las urbes y se ha desconocido la posibilidad de conformación en otros espacios como las áreas rurales y periféricas. Por lo tanto, este trabajo invita a explorar el territorio del noroccidente de Quito desde sus dinámicas económicas y productivas para evidenciar elementos o variables que conforman una centralidad, jerarquía o desequilibrios en las ruralidades.

El analizar el territorio desde sus dinámicas que lo atraviesan permite considerar la construcción social e histórica del mismo y comprender mejor la conformación de las centralidades, sus manifestaciones y efectos. La lectura de las centralidades en la ruralidad del noroccidente de Quito, desde las dinámicas económicas y productivas, evidencian como la concentración de bienes, actividades y servicios dentro de las parroquias rurales pueden también generar procesos o flujos internos y externos que ocasionan diferencias, cambios y/o transformaciones en los contextos y realidades entre territorios. Asimismo se ha podido constatar que las parroquias de Gualea y Nanegal presentan dos grandes problemáticas: por un lado, no han sido territorios centrales - de centralidad - para el Distrito Metropolitano de Quito; por otro, tampoco se ha potenciado su capital social como recurso para existir, mantenerse y crecer como territorio. 
Esperando que esta lectura territorial en torno a las centralidades en la ruralidad en el noroccidente de Quito pueda contribuir a la ampliación de líneas de reflexión-investigación sobre la relación centro-periferia entre lo nacional-local, donde se reflejan asimetrías más allá de las brechas de cobertura entre los servicios correspondientes a cada localidad (por ejemplo, entre Quito y Gualea), en el sentido de que expresan las necesidades, intereses e intencionalidades políticas del Estado-Nación y la consolidación de su hegemonía institucional por sobre las demandas y exigencias de las poblaciones locales, razón por la cual, si ambas escalas están sintonizadas entre sí, se verían cada vez más cerca del desarrollo desde la perspectiva nacional. Y lo que determina la pertinencia o relevancia de la política pública en los territorios es la consolidación del capital dentro del sistema capitalista de acumulación de recursos, bienes y servicios. Así, será la funcionalidad que represente el territorio, la que mande, ordene u organice lo territorial - descentralización, desconcentración-. Existiendo localidades más «aventajadas» que otras, las mismas que a su vez tendrán que «entregar» al entramado económico sus recursos naturales, mano de obra y productos, muchas veces ni siquiera a un precio justo. $\mathrm{Y}$ el encargado de regular y controlar las relaciones del mercado es precisamente el Estado, convirtiéndose en juez y parte del progreso de los pueblos, más aún en el caso de las dinámicas y transacciones alrededor de actividades como la minería, que involucran concesiones y recursos financieros que van directamente a las arcas estatales.

\section{NOTAS}

1 La información presentada en este artículo se basa en insumos teóricos y de investigación de campo de la tesis de maestría realizada en el Noroccidente de Quito (Gualea y parroquias aledañas) en el 2014. El trabajo de investigación tenía como uno de sus objetivos determinar las dinámicas territoriales sociales y económicas de la parroquia de Gualea a partir de los actores sociales y sus relaciones con el contexto y las parroquias aledañas. De manera específica, en la construcción de las dinámicas económicas-productivas, se realizaron entrevistas semiestructuradas -13 individuales y 1 grupal - a miembros de asociaciones de actividades productivas e informantes claves de la comunidad.

2 La selección de variables para la lectura de las dinámicas territoriales económicas productivas, hace hincapié en información sistematizada de la investigación de maestría, que reflejan significativas diferencias y/o relaciones de desigualdad entre la parroquia de Gualea y los territorios aledaños del Noroccidente de Quito. Las variables que se consideraron en la lectura de las dinámicas territoriales sociales y económicas-productivas de la investigación de maestría fueron: agricultura —caña de azúcar, café, autoconsumo-, ganadería bovina de leche y de carne; otras actividades productivas: turismo, organización, mercados y redes de comercialización; minería; tenencia de la tierra y tenencia del agua; acceso a servicios básicos; distribución y tasas de crecimiento poblacional; infraestructura y acceso a servicios sociales de la educación;, infraestructura y acceso a servicios de la salud y conformación de organizaciones sociales.

\section{REFERENCIAS}

Carrión, F. (1987). Quito, crisis y política urbana. Quito, Ecuador: Editorial El Conejo.

Castells, M. (1995). La crisis, la planificación y la calidad de vida: el manejo de las nuevas relaciones históricas entre espacio y sociedad. Revista Mexicana de Sociología, 46(4), 35-66.

Castells, M. (2001). La era de la información. Vol. I. La Sociedad Red. México DF, México: Siglo xxi.

Centro Latinoamericano para el Desarrollo Rural, RIMISP. (2008). Investigación aplicada de Dinámicas 
Territoriales Rurales en América Latina: Marco Metodológico (Versión 2), Programa Dinámicas Territoriales Rurales. Santiago de Chile, Chile: RimisP.

Christaller, W. (1933). La teoría de los lugares centrales. En M. J. Aguilera (Comp.), Geografía General II. Madrid, España: Universidad Nacional de Educación en Distancia.

Echarte, L. (1977). Relaciones de producción en Pacto y Nanegal: comunidades campesinas del noroccidente de Pichincha. (Tesis de pregrado). Pontificia Universidad Católica del Ecuador, Quito, Ecuador.

Espinosa, M. (2005). El pueblo donde nacen las nubes: historia local de Nanegalito. Quito, Ecuador: Municipio del Distrito Metropolitano de Quito.

Harvey, D. (1998). La condición de la posmodernidad. Investigación sobre los orígenes del cambio cultural. Buenos Aires, Argentina: Amorrortu.

Instituto de la Ciudad de Quito (2012). Estudio sobre las dinámicas productivas territoriales rurales en el DMQ. Tomo I. Quito, Ecuador: s. e.

Lefebvre, H. (1973). El derecho a la ciudad. Barcelona, España: Edicions 62.

Massa, D. (2014). La centralidad rural de la microrregión del noroccidente del Distrito Metropolitano de Quito: modelos de desarrollo, procesos e influencias en las dinámicas sociales y económicas territoriales: caso parroquia de Gualea. (Tesis de maestría). Recuperada de Repositorio digital de FLACso http://repositorio. flacsoandes.edu.ec/handle/10469/7591\#.VzzooyHp3To

Raffestein, C. (2011). Por una Geografía del Poder. Michoacán, México: Colegio de Michoacán.

Sosa, M. (2012). ¿Cómo entender el territorio? Guatemala, Guatemala: Parens-Universidad Rafael Landívar.

Gobierno Autónomo Descentralizado Parroquial Gualea (2012). Plan de Desarrollo y Ordenamiento Territorial Parroquia Gualea. Gualea, Ecuador: s. e.

Gobierno Autónomo Descentralizado Parroquial Nanegal (2010). Plan de Desarrollo y Ordenamiento Territorial Parroquia Nanegal. Nanegal, Ecuador: s. e.

Gobierno Autónomo Descentralizado Parroquial Nanegalito (2012). Plan de Desarrollo y Ordenamiento Territorial Parroquia Nanegalito. Nanegalito, Ecuador: s. e.

Gobierno Autónomo Descentralizado Parroquial Pacto (2012). Plan de Desarrollo y Ordenamiento

Territorial Parroquia Pacto. Pacto, Ecuador: s. e.

SENPlades (2009). Plan Nacional del Buen Vivir, 2009-2013. Quito, Ecuador: s. e.

SENPLAdes (2013). Plan Nacional del Buen Vivir, 2013-2017. Quito, Ecuador. s. e. 
